\title{
Documentary and instrumental-based drought indices for the Czech Lands back to AD 1501
}

\author{
Rudolf Brázdil ${ }^{1,2, *}$, Petr Dobrovolný ${ }^{1,2}$, Miroslav Trnka ${ }^{2,3}$, Ulf Büntgen ${ }^{2,4,5}$, \\ Ladislava Rezníčková ${ }^{1,2}$, Oldřich Kotyza ${ }^{6}$, Hubert Valášek ${ }^{1,7}{ }^{1}$, Petr Štěpánek ${ }^{2,8}$
}

\author{
${ }^{1}$ Institute of Geography, Masaryk University, Kotlářská 2, 61137 Brno, Czech Republic \\ ${ }^{2}$ Global Change Research Institute, Czech Academy of Sciences, Bělidla 986/4a, 60300 Brno, Czech Republic \\ ${ }^{3}$ Department of Agrosystems and Bioclimatology, Mendel University in Brno, Zemědělská 1, 613 00 Brno, Czech Republic \\ ${ }^{4}$ Swiss Federal Research Institute for Forest, Snow and Landscape WSL, Zürcherstrasse 111, 8903 Birmensdorf, Switzerland \\ ${ }^{5}$ Oeschger Centre for Climate Change Research, Falkenplatz 16, 3012 Bern, Switzerland \\ ${ }^{6}$ Regional Museum, Dlouhá 173, 41201 Litoměřice, Czech Republic \\ ${ }^{7}$ Moravian Land Archives, Palackého nám. 1, 62500 Brno, Czech Republic \\ ${ }^{8}$ Czech Hydrometeorological Institute, Kroftova 43, 61667 Brno, Czech Republic
}

\begin{abstract}
This study addresses the reconstruction of 4 slightly different drought indices in the Czech Lands (now the Czech Republic) back to 1501 AD. Reconstructed monthly temperatures for Central Europe that are representative for the Czech territory, together with reconstructed seasonal precipitation totals from the same area, are used to calculate monthly, seasonal and annual drought indices (SPI, SPEI, Z-index, and scPDSI). The resulting time series reflect interannual to multi-decadal drought variability. The driest episodes cluster around the beginning and end of the 18th century, while 1540 emerges as a particularly dry extreme year. The temperature-driven dryness of the past 3 decades is well captured by SPEI, Z-index and ScPDSI, whereas precipitation totals show no significant trend during this period (as reflected in SPI). Data and methodological uncertainty associated with Czech drought indices, as well as their position in a greater European context, are critically outlined. Comparison with fir tree-rings from southern Moravia and a spatial subset of the 'Old World Drought Atlas' (OWDA) reveals statistically significant correlation coefficients, of around 0.40 and 0.50 , respectively. This study introduces a new documentary-based approach for the robust extension of standardised drought indices back into pre-instrumental times, which we also believe has great potential in other parts of the world where high-resolution paleoclimatic insight remains limited.
\end{abstract}

KEY WORDS: Documentary evidence $\cdot$ Climate reconstruction $\cdot$ Drought variability $\cdot$ Extreme years $\cdot$ Central Europe

\section{INTRODUCTION}

Although the fifth IPCC report (Stocker et al. 2013) indicates the Mediterranean region is one of the most drought-prone areas of Europe, based on recent global warming projections, drought indices also indicate an important increase in drought in Central Europe from the year 2000, as has been shown,

*Corresponding author: brazdil@sci.muni.cz for example, for the territory of the Czech Republic (e.g. Brázdil et al. 2009, 2013a, 2015b, Brázdil \& Trnka 2015, Trnka et al. 2015a,b, Zahradníček et al. 2015). The distinctiveness of this phenomenon can only be evaluated on the basis of long-term drought reconstructions in which documentary data are combined with either instrumental records (Brázdil et al. 2013a) or with dendrochronological analyses of the

(C) The authors 2016. Open Access under Creative Commons by Attribution Licence. Use, distribution and reproduction are unrestricted. Authors and original publication must be credited. 
rings of trees sensitive to hydroclimatic patterns in their area of growth (Brázdil et al. 2002, Büntgen et al. 2010, 2011a, Cook et al. 2015, Dobrovolný et al. 2015b).

Several drought indices have been developed for the detection, monitoring and evaluation of drought episodes (for overviews, see e.g. Byun \& Wilhite 1999, Heim 2000, 2002, Vogt \& Somma 2000, Wu et al. 2007, Niemeyer 2008). Instrumentally derived data related to meteorological variables (particularly temperature and precipitation) or hydrological variables (discharge, groundwater level) are employed in their calculation. Although the indices thus created are able to describe various aspects of meteorological, agricultural, hydrological and groundwater droughts (Heim 2002, Mishra \& Singh 2010, Dai 2011), none of them can be used across the board. The differences among them arise out of the input data used, the intervals for which the values of the indices are integrated and the ways in which each individual index is calculated. Such indices are thus usually selected with respect to the aims of any given study, or aspects under particular investigation.

Although documentary data sources for Central Europe are particularly rich (Brázdil et al. 2005, 2010), the reliable documentary drought proxies provided by formal religious supplications for rain (rogations), so marked in the Mediterranean areas, for example (Piervitali \& Colacino 2001, Barriendos 2005, Domínguez-Castro et al. 2008, 2010, Diodato \& Bellocchi 2011) are absent. The creation of drought indices for the former area must therefore rely upon combined descriptions of temperature and precipitation patterns derived from a range of documentary sources that may provide series of temperature and/ or precipitation indices, as has been done, for example, for Switzerland (Pfister 1988, 1999), Germany (Glaser 2001, 2008) and the Czech Lands (Dobrovolný et al. 2009). Temperature indices for all 3 of these territories have been used, together with instrumental measurements, to create a temperature series for Central Europe (Dobrovolný et al. 2010). Similarly, precipitation indices combined with precipitation measurements have been used to calculate precipitation series for the Czech Lands (Dobrovolný et al. 2015a). Despite their considerable potential for the study of long-term drought fluctuations, to date their only direct use for this purpose has been for the creation of a 512-yr drought frequency chronology for the Czech Lands (Brázdil et al. 2013a). However, in this case, only simple sums of negative precipitation indices on a decadal scale were used to express the measure of drought severity.
More recently, Wetter et al. (2014) coined the term 'megadrought' for the extremely dry year that occurred in Europe in 1540. Büntgen et al. (2015) expressed some doubts about the use of this term because no clear sign of such an extreme appeared in many existing tree-ring chronologies for that particular year. However, Pfister et al. (2015) provided support for the original results from documentary data, citing inconsistencies in the identification of extreme years in tree-ring data derived from different tree species, regions and periods analysed. In making such comparisons, it should be borne in mind that, documentary data are not restricted to a particular time of year. On the other hand, tree-rings may be used to reconstruct drought indices far beyond the period covered by documentary data (e.g. Büntgen et al. 2011b, Dobrovolný et al. 2015b). More recently, Cook et al. (2015) developed the 'Old World Drought Atlas' (OWDA), in which they produced year-to-year maps of summer wetness and dryness in Europe and the Mediterranean during the Common Era, expressed in terms of self-calibrated Palmer Drought Severity Index (scPDSI) values reconstructed from 106 tree-ring series. In this context, reconstruction of drought indices based on documentary data may provide an important contribution to the study of past and recent droughts, comparable with other existing drought reconstructions.

This study aims to fill a gap in existing pre-instrumental drought reconstructions for Europe. It provides a 515 yr series of drought indices for the Czech Lands based on combined temperature and precipitation reconstructions derived from documentary and instrumental data.

\section{DATA AND METHODS}

Four slightly different drought indices are employed in this contribution: the Standardised Precipitation Index (SPI, McKee et al. 1993), the Standardised Precipitation Evapotranspiration Index (SPEI, Vicente-Serrano et al. 2010), Palmer's Z-index, and the self-calibrated version of the Palmer Drought Severity Index (PDSI) (Palmer 1965). Calculations of these were based on $~ 500$-yr temperature and precipitation reconstructions, as described below. The selected indices are those used the most frequently in drought studies and express various aspects of drought. The SPI, calculated from monthly precipitation totals, can be interpreted as the number of standard deviations by which the observed precipitation anomaly deviates from the long-term mean. The SPEI 
is analogue of the SPI, but instead of precipitation only it is based on monthly differences between precipitation and potential evapotranspiration. Therefore it represents anomaly of the climatological water balance. The Z-index is principally used to express soil moisture anomaly, depending on the difference between precipitation and potential evapotranspiration, i.e. it evaluates the deviation from climatological optimum, which reflects prevailing patterns at the assessed site in the particular month (Palmer 1965). Compared to more frequently used PDSI it represents only the current state of the water balance, without considering the antecedent soil moisture status.

Temperature series for Central Europe were created by means of reconstructions at the monthly level by Dobrovolný et al. (2010). Included in this calculation were index series for Switzerland (Pfister 1988), Germany (Glaser 2001) and the Czech Lands from 1501 to 1854, combined with homogenised mean temperature series from eleven central European stations (including Czech Prague-Klementinum) covering the period 1760-2007. The application of simple linear regression, calibration and verification interval enabled the 1760-1854 period to be included, with a high share of explained variance (between $86 \%$ in January and $56 \%$ in September). This series for AD 1500-2007 has proven quite representative for Central Europe and the Czech Lands due to high spatial temperature correlations in this region. It was impossible to extend the central European temperature series (Dobrovolný et al. 2010) beyond 2007 using the original instrumental data from the 11 stations, so the series was taken to December 2010 by means of linear regression with the mean Czech Land temperature series (see Brázdil et al. 2012a, 2012b) and subsequently extended to cover the period January 2011-August 2015. Statistically significant correlation coefficients between the 2 series fluctuated from 0.90 (September) to 0.96 (February) in the 1800-2007 common period. In general, higher correlation coefficients were typical of winter, while lower values emerged in summer. This is due to the fact that winter temperature patterns are mainly related to strongly expressed macro-scale circulation patterns, while the influence of meso- or micro-scale effects related to sunshine duration or cloudiness increases in summer.

Precipitation series, of greater spatial variability than temperature series in Central Europe, were used for reconstruction only for the Czech Lands (Dobrovolný et al. 2015a). The limited available documentary data meant that it was only possible to create precipitation indices at seasonal level (DJF, MAM, JJA, SON) for the 1501-1854 period. While instrumentally-based mean precipitation series for the Czech Lands exist from 1804 (Brázdil et al. 2012a, 2012b), the overlap between documentary and instrumental data is limited to the 1804-1854 period (explained variance between $35 \%$ in JJA and $26 \%$ in DJF). Nevertheless, the reconstruction obtained adequately represents precipitation in the Czech Lands in $\mathrm{AD}$ 1501-2010. The precipitation series for the Czech Lands up to 2010 (Brázdil et al. 2012a, 2012b) was further extended to January 2011-August 2015.

The calculation of SPI requires monthly precipitation totals, while SPEI, Z-index and PDSI need monthly temperature means as well. While temperature data were estimated from documentary data for each month (Dobrovolný et al. 2010), the documentary sources for precipitation provided only seasonally-resolved data between 1501 and 1803 (Dobrovolný et al. 2015a). In order to estimate the likely distribution of seasonal precipitation totals among individual months and to create proxy monthly records, the Czech mean monthly series from the 1875-1974 instrumental period were employed, i.e. from the period with a sufficiently dense observational network. The proportions of precipitation for individual months of the season for each year between 1875 and 1974 were calculated on the basis of the observed monthly precipitation totals. For example, in the spring of 1875, March achieved $29 \%$ of the MAM total, April $25 \%$ and May $46 \%$; in the spring of 1876, these figures were $35 \%$ in March, $32 \%$ in April and $33 \%$ in May; etc. The next step was to create a 100-member ensemble of monthly precipitation totals for each season and year between 1501 and 1803, dividing the seasonal precipitation according to the recorded monthly precipitation in individual years during the 1875-1974 period. Monthly precipitation totals for 1804-2015 were then added to every 100-series for 1501-1803.

SPI, SPEI, Z-index and scPDSI were then calculated by standard procedure with distribution calibrated to 1875-2014; however, this was done separately for each of the 100 realisations. Median and 5th and 95th percentiles from the 100-series were further estimated and used for 1501-1803, while after 1804 the calculated drought indices for all 100-series were identical. Only aggregations of SPI and SPEI for periods of 3 mo and longer were used for further analysis, significantly reducing the noise introduced by monthly precipitation estimated from seasonal totals. In all cases, the variation in water balance was aggregated and evaluated for seasons and years individually and examined carefully. It must be noted that all the major drought/wet episodes are present in the record 
regardless of ensemble membership. For all analyses in this study, series of drought indices calculated as median for 1501-1803 were extended further from 1804 to 2015 by indices derived from instrumental data.

The series of drought indices calculated were further divided into 3 groups, categorising the various types of drought:

(1) Short-term drought: seasonal series (DJF, MAM, JJA, SON) in terms of SPI-3, SPEI-3 and Z-index

(2) Medium-term drought: summer half-year (April-September) series in terms of SPI-6, SPEI-6 and Z-index

(3) Long-term drought: annual series in terms of SPI-12, SPEI-12 and scPDSI

Short-term drought (particularly for MAM and JJA) is used to represent agricultural drought (e.g. Brázdil et al. 2009, Hlavinka et al. 2009) affecting cereal and fodder crops in the region. Medium-term drought (April-September) has impacts on forests (e.g. Rybníček et al. 2015) and perennial cultures, including grapevines (e.g. Možný et al. 2016 this Special). Longterm drought indicators indicate hydrological drought with likely impacts on rivers and overall water availability. This division follows, to some degree, suggestions made by Heim (2002), who argued that each type of drought (meteorological, agricultural, hydrological and socio-economic) requires its own specific set of indicators. As each of these represents a different facet of drought, the most notable drought episodes will differ somewhat, as will — to some degree - the most/least drought affected periods.

The series of drought indices were further used for basic statistical analyses. Their temporal fluctuations were smoothed by 20 yr Gaussian filter, by calculation of linear trends and by selection of extremely dry years. For the pre-instrumental period, the grey area in Figs. 1-3 (see Section 3.1) expresses the interval between 5th and 95th percentiles of reconstructed values, thus identifying the confidence interval of $90 \%$ for reconstructed values. Comparison of drought index series with other reconstructions was based on 30 yr running correlation coefficients.

\section{RESULTS}

\subsection{Drought variability}

Fig. 1 shows fluctuations in the reconstructed Czech seasonal SPI-3, SPEI-3 and Z-index describing short-term (seasonal) droughts in the Czech Lands. These 3 indices correlate best in summer (between
0.97 for SPEI-3 with Z-index and 0.94 for SPI-3 with Z-index), while the lowest correlations appear in winter $(0.67$ and 0.71 for Z-index with SPI-3 and SPEI-3, respectively; but 0.96 for SPI-3 with SPEI-3). Inter-annual and inter-decadal variability is wellexpressed in all series, while any statistically significant linear long-term trend is absent. Series smoothed by 20 yr Gaussian filter are very similar in the character of fluctuations and in alternation of relatively drier and wetter periods. The driest 30-yr periods for seasonal SPI-3 and SPEI-3 are more or less identical, although occurring in different sections of the period studied: 1680-1709 for DJF, 1774-1803 for MAM (1773-1802 for Z-index), 1700-1729 for JJA (also for Z-index) and 1605-1634 for SON. The driest $30 \mathrm{yr}$ periods in terms of the Z-index occur in 1702-1731 in DJF and for 1699-1728 in SON. Although the final decades of the late 20th and early 21st centuries show a clear tendency towards increasing dryness in terms of SPEI-3 and the Z-index in all seasons except winter, they are less dry than the driest $30 \mathrm{yr}$ periods, which concentrate markedly around the decades at the beginning and end of the 18th century.

The reconstructed series for the summer half-year (April-September), i.e. the SPI-6, SPEI-6 and Zindices that characterise medium-term droughts (Fig. 2), do not differ much from the fluctuations in short-term droughts. The driest $30 \mathrm{yr}$ periods are also very similar: 1773-1802 for SPI-6 and SPEI-6 and 1700-1729 for Z-index. This indicates that severe droughts in MAM and JJA significantly influence the character of drought for the whole summer half-year. The slightly increasing dryness of past decades is not expressed in SPI-6 values. All 3 drought indices correlate to a high degree: 0.98 for SPEI- 6 with Z-index and 0.93 for the 2 remaining combinations of indices.

Fig. 3 shows fluctuations in reconstructed series of annual Czech drought indices, i.e. in terms of SPI-12, SPEI-12 and ScPDSI. SPI-12 correlates closely with SPEI-12 (0.92); the correlations with scPDSI are 0.85 for SPEI-12 and 0.78 for SPI-12. Although SPI-12 and scPDSI indicate that the driest decades and 30-yr periods fell in the early 18th century (1704-1733), SPEI-12 shows more dryness in recent decades (1986-2015). This index captures the effect of increasing temperature means while precipitation totals remain more or less stable (see SPI-12). The steep decrease in fluctuations of annual scPDSI in 1727-1729 is particularly remarkable, and without parallel in the past $515 \mathrm{yr}$. This is a cumulative result of years with dry episodes occurring between 1724 and 1728 (compare with Brázdil et al. 2013a; for a description of the extremely dry year of 1726, see Brázdil \& Trnka 2015). 

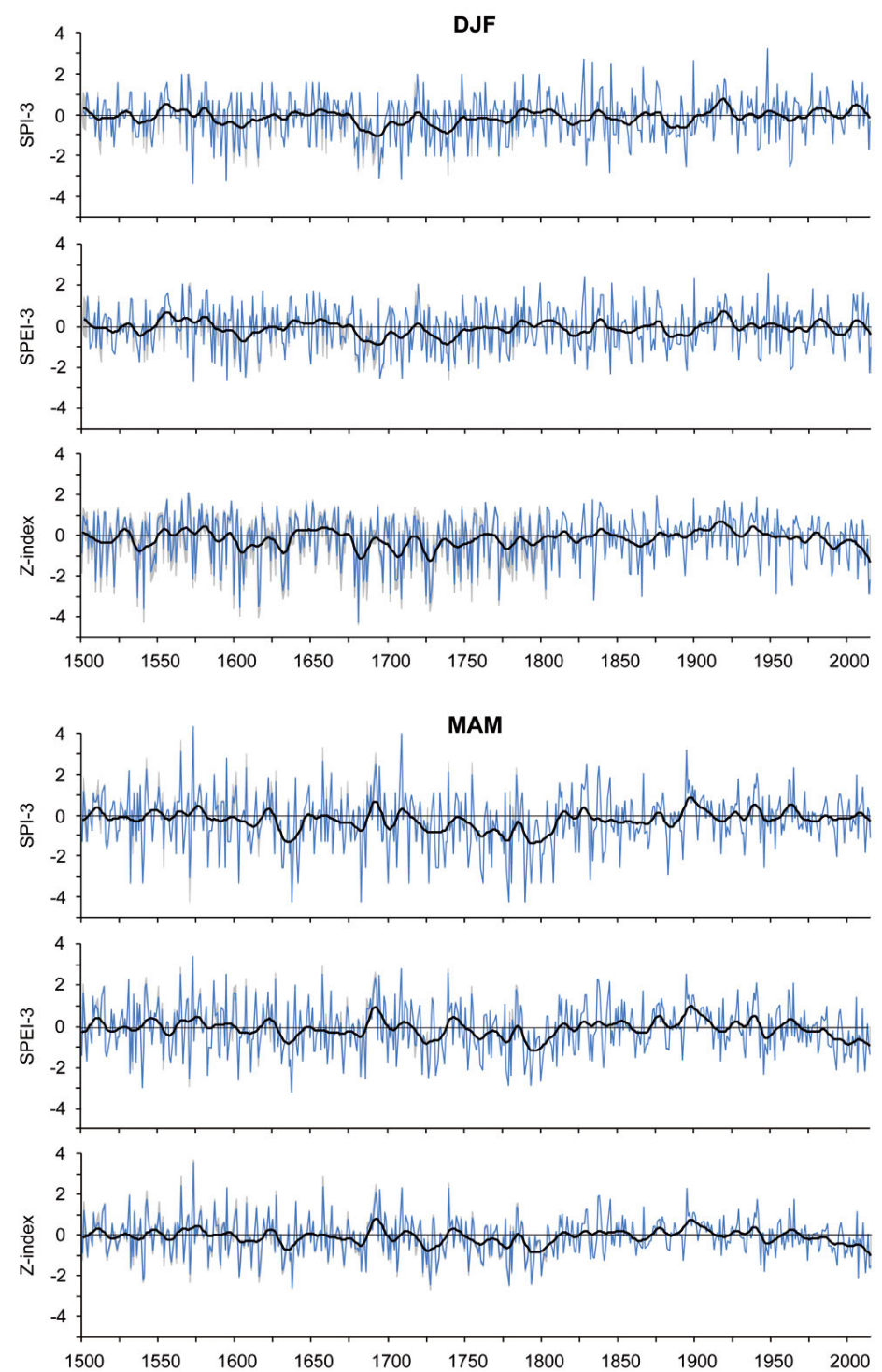
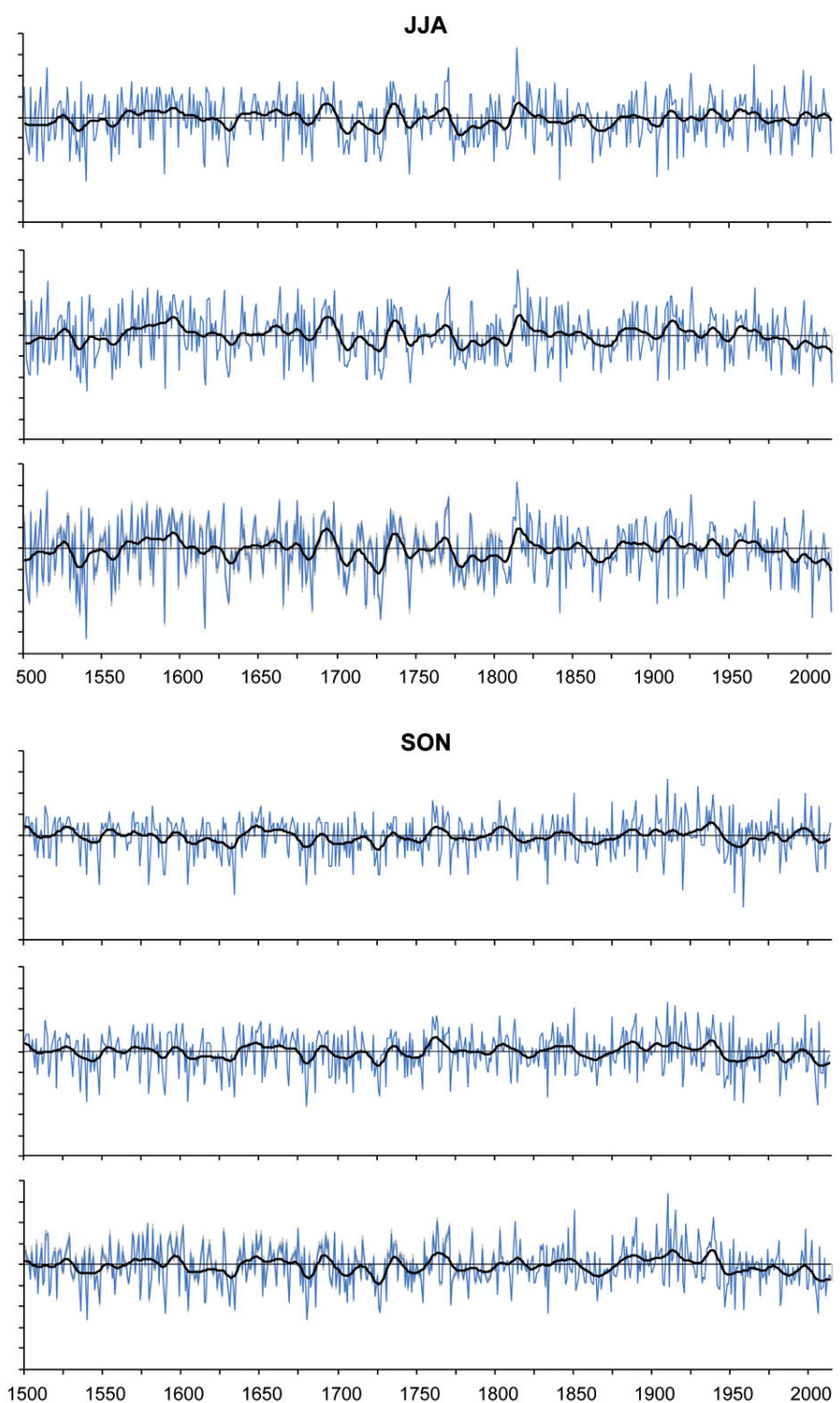

Fig. 1. Fluctuations in reconstructed series of Czech seasonal drought indices (SPI-3, SPEI-3 and Z-index as indicators of shortterm drought) in the 1501-2015 period (SON: to 2014) smoothed by 20-yr Gaussian filter. For the pre-instrumental period

(1501-1803), 5th and 95th percentiles approximate to $90 \%$ confidence intervals (in grey)

\subsection{Drought extremes}

Using the reconstructed series of Czech drought indices, it was possible to identify the driest years in the entire 1501-2015 period. The 10 driest years were selected from each series used. For every group of drought indices, these 10 extreme years were then weighted in order of severity for all 3 indices (e.g. SPI-3, SPEI-3 and Z-index for JJA) to obtain their total weight, allowing the creation of a final order for the whole group. The 5 most important events in terms of short-term, medium-term and long-term droughts could then be identified.
The results, shown in Table 1, highlight the severity of the 1540 drought, which figures prominently in all cases except DJF, and was the most extreme drought in JJA and the summer half-year. It was identified by one or more indices as the most severe drought in JJA (SPI-3, SPEI-3, Z-index), SON (Zindex), the summer half-year (SPI-6, SPEI-6, Zindex) and annual series (SPI-12, SPEI-12) (Table 2). This event, which had particularly significant manifestations and impacts in western and Central Europe, has been described as a 'megadrought' on the European scale by Wetter et al. (2014). Detailed documentary testimony exists as to its effects in the 


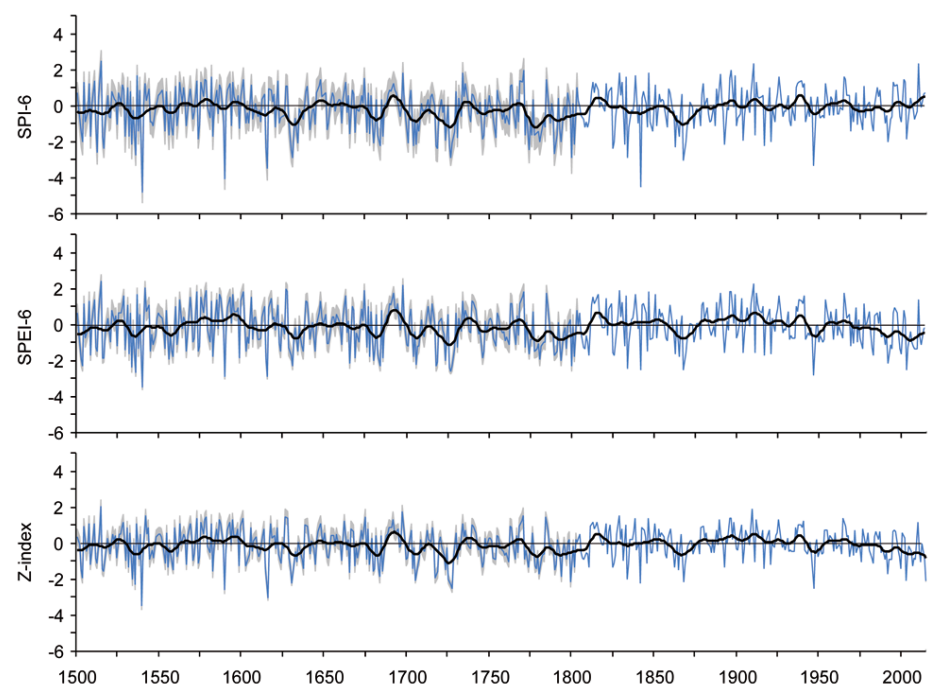

Fig. 2. Fluctuations in reconstructed series of Czech summer half-year drought indices (SPI-6, SPEI-6 and Z-index as indicators of medium-term drought) in the 1501-2015 period, smoothed by 20 yr Gaussian filter. For the pre-instrumental period, 5th and 95th percentiles approximate to $90 \%$ confidence intervals (in grey)

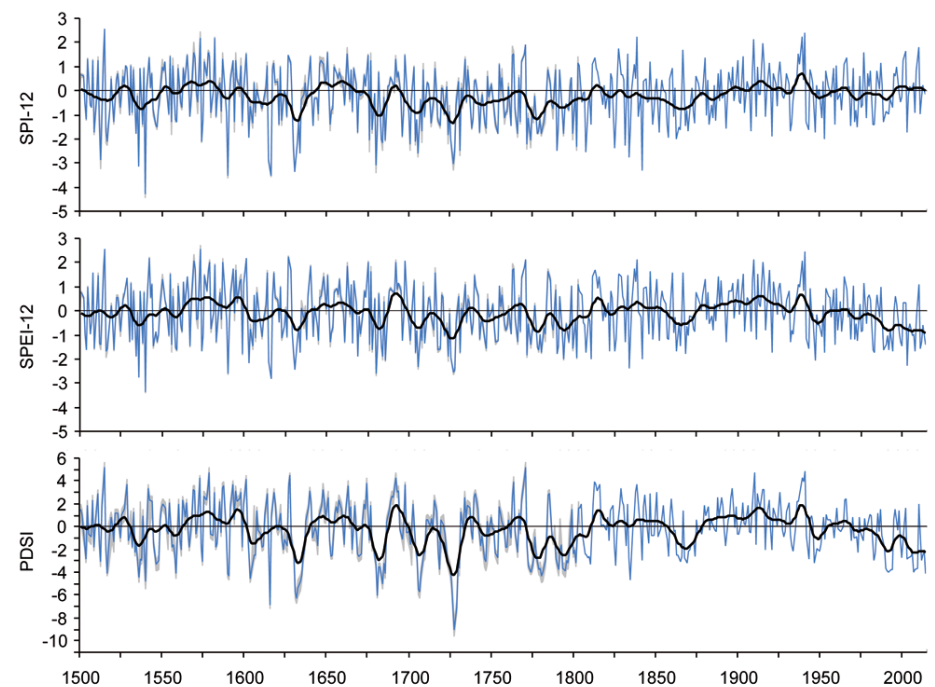

Fig. 3. Fluctuations in reconstructed series of Czech annual drought indices (SPI-12, SPEI-12 and scPDSI as indicators of long-term drought) in the 1501-2014 period, smoothed by $20 \mathrm{yr}$ Gaussian filter. For the pre-instrumental period, the 5th and 95th percentiles approximate to $90 \%$ confidence intervals (in grey)

Czech Lands (Brázdil et al. 2013a, 2013b). For further discussion of the 1540 'megadrought' in Europe see more recent papers by Büntgen et al. (2015) and Pfister et al. (2015).

The severe drought of 1540 in JJA, summer halfyear and annual indices in the Czech Lands was followed by two further droughts of significance in 1590
Table 1 . The 5 driest seasonal, summer half-year and annual droughts in the 1501-2015 period, based on reconstructed series of Czech drought indices. STD: short-term drought (3 mo); MTD: medium-term drought (6 mo); LTD: long-term drought (1 yr)

\begin{tabular}{|cccccccc|}
\hline \multirow{2}{*}{ Order } & \multicolumn{4}{c}{ STD } & & MTD & LTD \\
\cline { 2 - 6 } & DJF & MAM & JJA & SON & & Apr-Sep & Annual \\
\hline 1 & $1572-73$ & 1638 & 1540 & 1680 & 1540 & 1616 \\
2 & $1594-95$ & 1779 & 1590 & 1959 & 1590 & 1540 \\
3 & $1708-09$ & 1540 & 1616 & 2006 & 1616 & 1590 \\
4 & $1680-81$ & 1794 & 1842 & 1540 & 1947 & 1631 \\
5 & $1694-95$ & 1603 & 2003 & 1605 and & 1727 and & 1727 \\
& & & & 1634 & 1842 & \\
\hline
\end{tabular}

and 1616 (for detailed descriptions, see Brázdil et al. 2013a,b). As Table 1 shows, together with the drought of 1540, these constitute the 3 most severe drought events in the entire 1501-2015 period. The list of most extreme droughts in JJA and the summer half-year is made up by droughts from the instrumental period, in 1842, 1947 and 2003 (for detailed descriptions, see Brázdil \& Trnka 2015, Brázdil et al. 2016 this Special). The most severe droughts in the remaining 3 seasons occurred in 1572-73 (DJF), 1638 (MAM) and 1680 (SON). The MAM event of 1638 was identified as the most severe spring drought by all 3 drought indices (SPI-3, SPEI-3, Z-index). In DJF and MAM, no event among the 5 driest years occurred within the instrumental period. In SON, droughts in the years 1959 and 2006 were the next most serious after that occurring in 1680. Further, scPDSI indicated no drought from the instrumental period occurring among the 5 most extreme years.

Details of the driest periods at regular annual, decadal, $30 \mathrm{yr}$ and $50 \mathrm{yr}$ time scales are shown for the respective indices in Table 2 . There is consistency among all three indices in identification of the driest decades for MAM (1791-1800), JJA (1531$1540)$ and annual drought indices (1721-1730). The decade 1721-1730 is also the driest in terms of the Z-index for DJF, SON, and the summer half-year and SPEI for SON and the summer half-year. For regular $30 \mathrm{yr}$ periods, 1771-1800 is identified as the driest period by 10 indices, while 1981-2010 and 16811710 are each identified as driest by 4 indices. The driest $50 \mathrm{yr}$ period is identified as occurring in 17011750 by 13 indices. $1751-1800$ is identified as the driest 50 yr period for MAM by 3 indices and by SPI- 6 for the summer half-year, while 1951-2000 was the driest according to SPEI-3 for SON. Among the centuries, the 18th century was identified as the driest in all drought indices. 
Table 2. Driest annual, decadal, $30 \mathrm{yr}$ and $50 \mathrm{yr}$ periods in the 1501-2015 period according to reconstructed series of individual Czech drought indices. STD: short-term drought; MTD: medium-term drought; LTD: long-term drought; SPI: Standardised Precipitation Index; SPEI: Standardised Precipitation Evapotranspiration Index; ScPDSI: self-calibrated Palmer Drought Severity Index

\begin{tabular}{|c|c|c|c|c|c|c|c|c|c|}
\hline \multirow[t]{2}{*}{ Period } & \multicolumn{3}{|c|}{ STD: DJF } & \multicolumn{3}{|c|}{ STD: MAM } & \multicolumn{3}{|c|}{ STD: JJA } \\
\hline & SPI-3 & SPEI-3 & Z-index & SPI-3 & SPEI-3 & Z-index & SPI-3 & SPEI-3 & Z-index \\
\hline $1 \mathrm{yr}$ & 1573 & 1573 & 1681 & 1638 & 1638 & 1638 & 1540 & 1540 & 1540 \\
\hline $10 \mathrm{yr}$ & $1691-1700$ & $1731-1740$ & $1721-1730$ & $1791-1800$ & $1791-1800$ & $1791-1800$ & $1531-1540$ & $1531-1540$ & $1531-1540$ \\
\hline $30 \mathrm{yr}$ & $1681-1710$ & $1681-1710$ & $1681-1710$ & $1771-1800$ & $1771-1800$ & $1771-1800$ & $1771-1800$ & $1981-2010$ & $1771-1800$ \\
\hline $50 \mathrm{yr}$ & $1701-1750$ & $1701-1750$ & $1701-1750$ & $1751-1800$ & $1751-1800$ & $1751-1800$ & $1701-1750$ & $1701-1750$ & $1701-1750$ \\
\hline \multirow[t]{2}{*}{ Period } & \multicolumn{3}{|c|}{ STD: SON- } & \multicolumn{3}{|c|}{ MTD: summer half-year- } & \multicolumn{3}{|c|}{ LTD: full year } \\
\hline & SPI-3 & SPEI-3 & Z-index & SPI-6 & SPEI-6 & Z-index & SPI-12 & SPEI-12 & scPDSI \\
\hline $1 \mathrm{yr}$ & 1959 & 1680 & 1540 & 1540 & 1540 & 1540 & 1540 & 1540 & 1728 \\
\hline $10 \mathrm{yr}$ & 1951-1960 & $1721-1730$ & $1721-1730$ & 1861-1870 & $1721-1730$ & $1721-1730$ & 1721-1730 & $1721-1730$ & $1721-1730$ \\
\hline $30 \mathrm{yr}$ & $1681-1710$ & $1981-2010$ & $1981-2010$ & $1771-1800$ & $1771-1800$ & $1771-1800$ & 1771-1800 & $1981-2010$ & $1771-1800$ \\
\hline $50 \mathrm{yr}$ & $1701-1750$ & $1951-2000$ & $1701-1750$ & $1751-1800$ & $1701-1750$ & $1701-1750$ & $1701-1750$ & $1701-1750$ & $1701-1750$ \\
\hline
\end{tabular}

\section{DISCUSSION}

\subsection{Spatial significance}

In the overall evaluation of reconstructed series of drought indices in the Czech Lands, it is important to consider their spatial interrelationships with other parts of Europe. Certain gridded seasonal drought indices for Europe are available that correlate with Czech series in the 1901-2012 period. Fig. 4 shows seasonal fields of correlation coefficients between Czech SPEI-3 and the Global SPEI Database (http:// sac.csic.es/spei/index.html, accessed 25 October 2015). Except for summer, the long belt of positive correlations extends laterally from France to Russia, north- or northeastwards from the Black Sea. In the summer the area of positive correlations tends to focus around Czech territory, with a small extension to the east. By contrast, negative correlations are apparent in the northwestern part of Norway. Different fields of correlation coefficients appear for seasonal SCPDSI, when compared with values from the CRU database (van der Schrier et al. 2006) (Fig. 5). The areas with positive correlations are much smaller and extend from the Czech territory to the southeast, almost as far as Greece. Other areas with positive correlation coefficients have a somewhat patchy and random distribution. Regions with negative correlations are mainly present over northern Europe (from the southern side of the Baltic Sea to the north).

It follows from Figs. 4 and 5 that it would be unreasonable to expect correlations between the indices used in this study and reconstructed series of precipitation totals for other areas, even close to the Czech territory, or drought indices for more distant areas.
However, some significant correlation coefficients (however, only around the 0.20 level) were found in comparisons of SPI, SPEI and Z-index series with a multiproxy precipitation reconstruction for Central Europe (Pauling et al. 2006), and tree-ring width reconstructions from Norway spruce Picea abies for the Bavarian Forest (Wilson et al. 2005) and from black pine Pinus nigra for the Vienna region (R. Wimmer pers. comm.).

\subsection{Multi-proxy comparison}

Reconstructed Czech drought indices show correlations of between 0.30 and 0.40 with reconstructions of March-July precipitation totals derived from the tree-ring widths of fir Abies alba Mill. in southern Moravia (Brázdil et al. 2002) and with the May-June Z-index (Büntgen et al. 2011a). Statistically significant correlation coefficients with the May-June Zindex fluctuate between 0.37 (SPI, SPEI) and 0.39 (Zindex), while correlation coefficients for March-July precipitation totals vary from 0.34 (SPI, Z-index) to 0.35 (SPEI). The use of $30 \mathrm{yr}$ running correlation coefficients between the series compared generally generates an unstable signal over time (Fig. 6). This is typical of comparisons between temperature and precipitation reconstructions based on documentary data or natural proxies (see e.g. Brázdil et al. 2010, Dobrovolný et al. 2010, 2015a). Both tree-ring reconstructions exhibit a marked drop in correlation with Czech drought indices in 1560-1600 and MarchJuly totals with SPI in the first half of the 18th century. High positive correlations occur particularly in the first half of the 17th century and for Z-index in the 

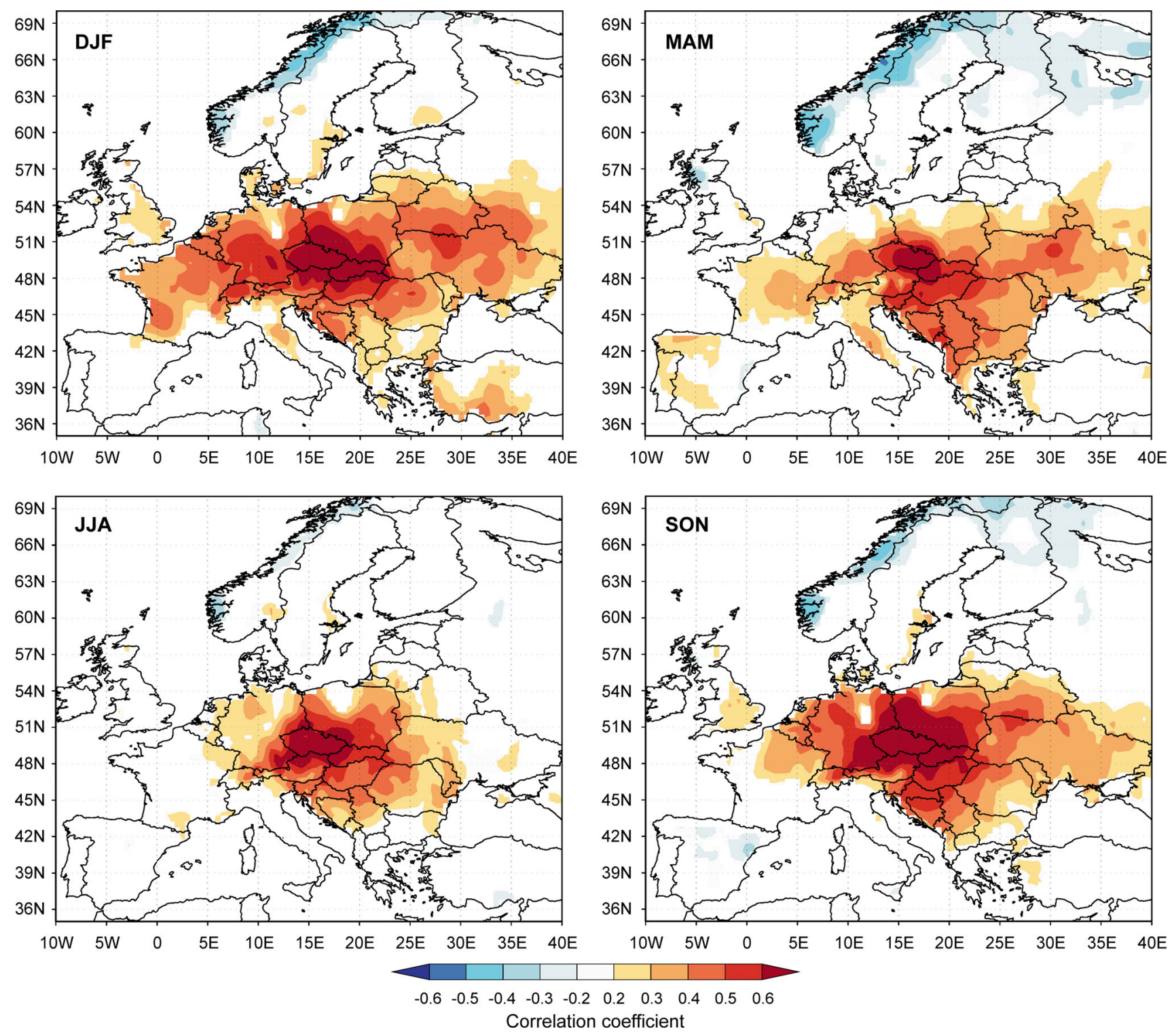

Fig. 4. Spatial correlations of seasonal Czech SPEI-3 series with SPEI-3 gridded series from the Global SPEI Database (http://sac.csic.es/spei/index.html, accessed 25 October 2015) in the 1901-2012 period

years $1750-1875$, after which a considerable decrease in correlation coefficient values is again apparent. Correlation coefficients of drought indices with precipitation totals in this second period are clearly below those with Z-index. The highest correlations of drought indices with March-July precipitation totals centred around 1925 give way to a steep decrease in correlation coefficients up to the second half of the 20th century, the result of a lost relationship between tree-rings and precipitation totals, as addressed by Brázdil et al. (2002).

The fluctuation of reconstructed series of Czech drought indices can also be compared with the $512 \mathrm{yr}$ Czech chronology of drought frequency for the sum- mer half-year created by Brázdil et al. (2013a). Cases in which at least 2 consecutive months were classified as dry, very dry or extremely dry were defined as dry episodes in the pre-instrumental period, while for the instrumental period, cases in which both SPEI-1 and Z-index had a return period of $\mathrm{N} \geq 2$ yr were used. On the decadal scale, $8 \mathrm{yr}$ with such dry episodes were recorded in 1801-1810 and $7 \mathrm{yr}$ in 1701-1710, 18611870, 1941-1950, 1991-2000 and 2001-2010. However, only 2 of these decades appeared among the 5 driest in reconstructed SPI-6, SPEI-6 and Z-index series for the summer half-year: in order of severity, these were 1721-1730, 1861-1870, 1531-1540, 17911800 and 1701-1710; the remaining decades, with 

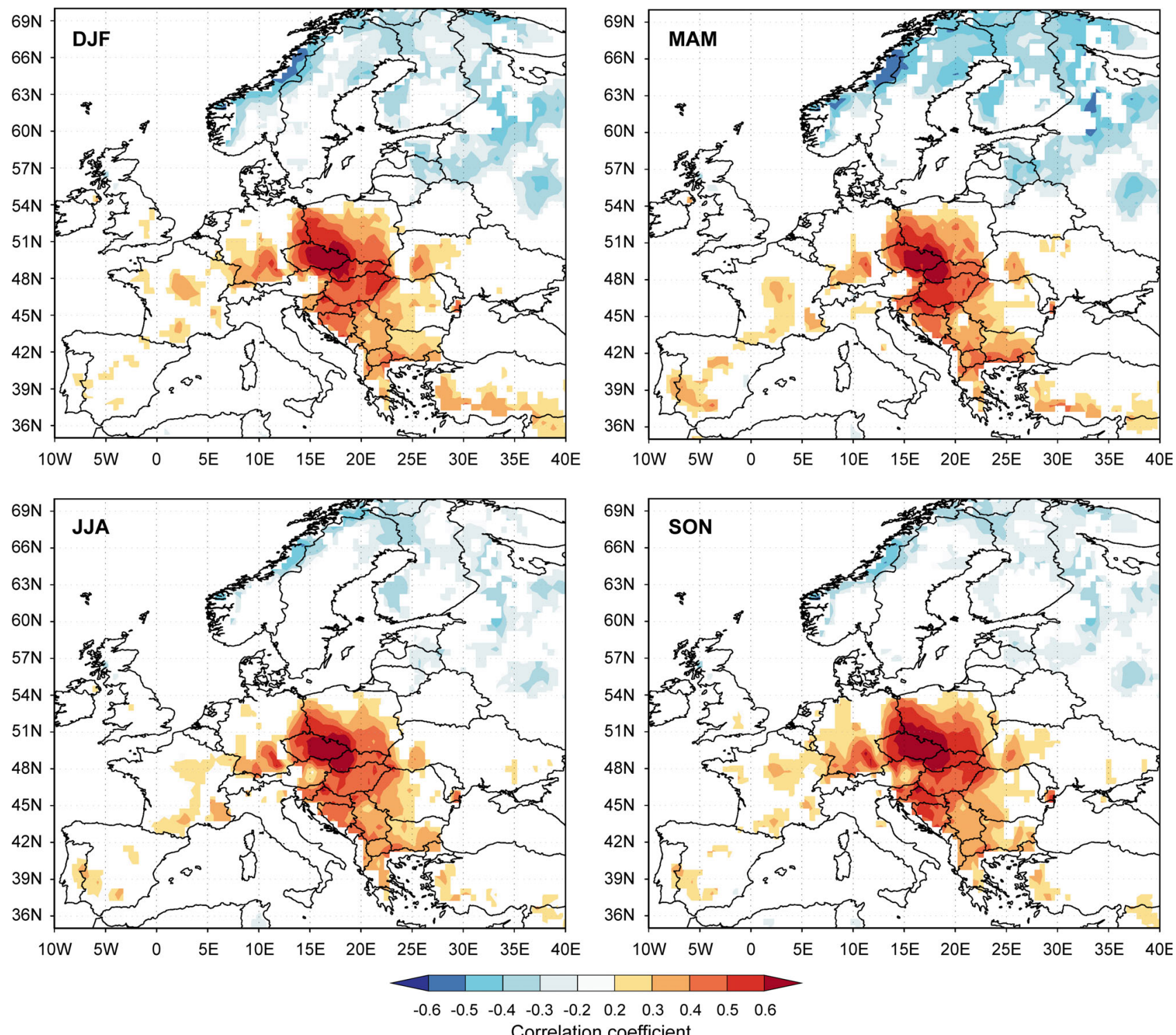

Fig. 5. Spatial correlations of seasonal Czech scPDSI series with seasonal scPDSI 3.21 gridded series from the CRU database (van der Schrier et al. 2006) in the 1901-2012 period

the exception of 1941-1950, appear in the list of the 10 driest decades for the summer half-year. Within $50 \mathrm{yr}$ periods (Table 2) there is a high frequency of dry episodes in 1751-1800 (25 yr) and 1701-1750 (24 yr), while 1951-2000, with 26 dry years, is among the driest periods if only SON is considered. A total of $49 \mathrm{yr}$ with episodes of drought in the 18th century render it the driest century in terms of Czech drought indices.

Significant correlation coefficients exist between drought indices and JJA scPDSI series reconstructed from tree rings in the European OWDA by Cook et al. (2015). Gridded data for the Czech Lands (CZs, 91 grids) and Central Europe (CEs, 421 grids) were used for calculation of 2 scPDSI series for comparison with reconstructed JJA SPEI-3 and Z-index, summer half-year SPEI-6 and Z-index, and finally with annual scPDSI. Fluctuations in $30 \mathrm{yr}$ running correlation coefficients of reconstructed drought indices with CZs are shown in Fig. 7 and with CEs in Fig. 8 for the 1501-2012 period. Statistically significant correlation coefficients with CZs are slightly higher than those with CEs. Correlations with CZs fluctuate between 0.54 for the summer half-year Z-index and 0.47 for annual scPDSI, compared to a range of correlations with CEs between 0.51 for JJA Z-index and 0.41 for scPDSI. It follows from these comparisons that the best agreement between Czech drought indices with 


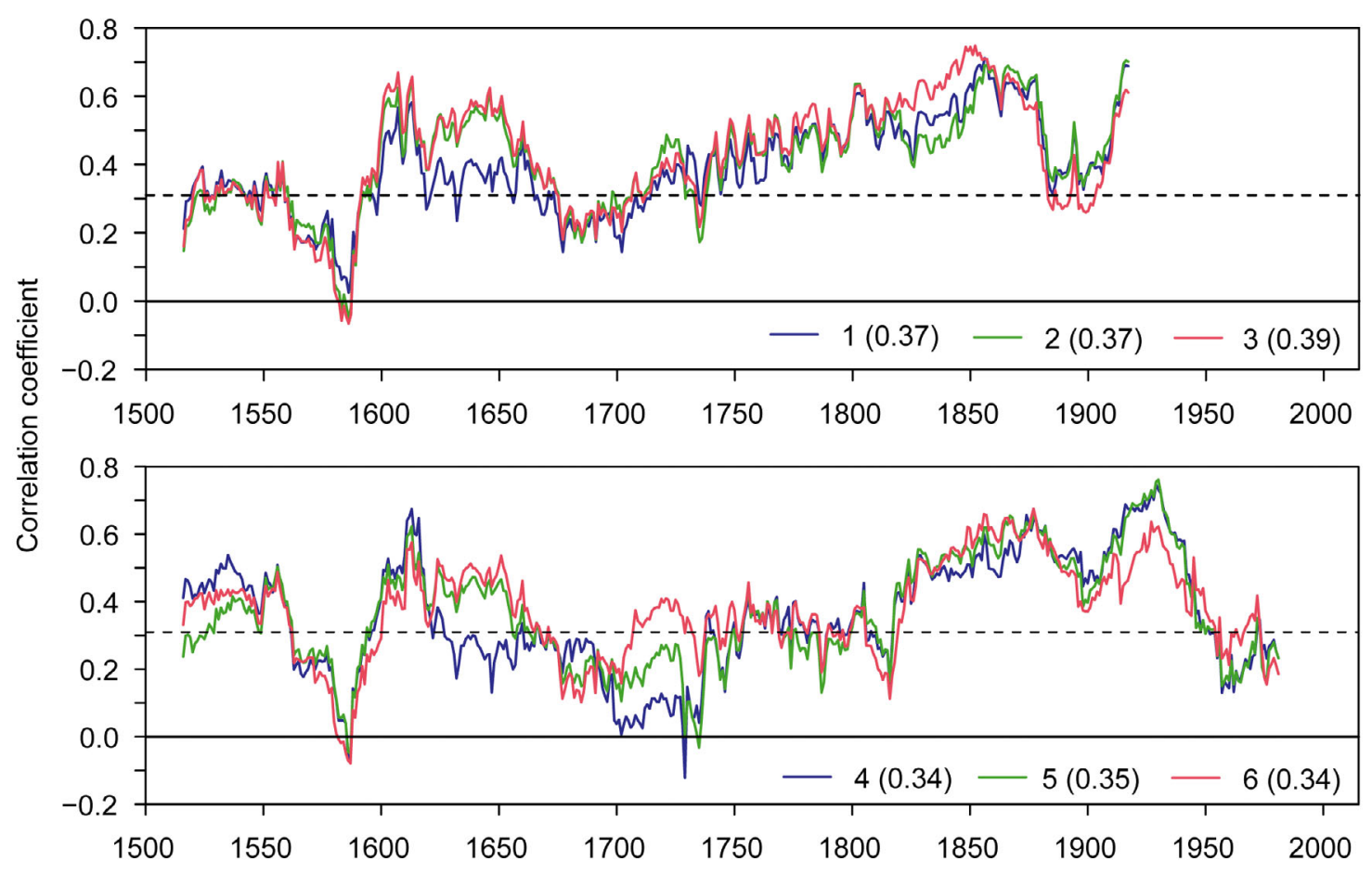

Fig. 6. Running 30 yr correlation coefficients of selected Czech drought index series with the May-June Z-index (1: SPI; 2: SPEI; 3: Z-index) and March-July precipitation totals (4: SPI; 5: SPEI; 6: Z-index) in southern Moravia derived from tree-ring widths of fir Abies alba Mill. (Brázdil et al. 2002, Büntgen et al. 2011a). Significant positive correlations appear above the broken horizontal line; correlation coefficients between corresponding series are indicated in parentheses

CZs and CEs occurs in the first half of the 16th century, during the 17th century, in the late 19th and early 20th centuries, and finally in $\sim 1950-1980$. Several important decreases in correlation values, even below the level of statistical significance, are apparent in the latter half of the 16th century, around 1700, mid-18th century and at its end. Despite this, the comparison clearly demonstrates the similarity between the Czech drought reconstructions based on documentary data and OWDA JJA scPDSI reconstructions based on tree-rings.

\subsection{Uncertainties in data and methods}

This study employs 4 separate drought indices, calculated from precipitation data or from a combination of temperature and precipitation, with the added possibility of including the influence of soil waterholding capacity. Indices including both temperature and precipitation not only allow the capture of drought driven by lack of rain, but also consideration of increased evaporative demand from the atmosphere. Such drought-stress reinforcement by higher temperatures is sometimes termed 'global-changetype drought' (Breshears et al. 2005). On the other hand, precipitation-based drought indices (including SPI) assume that variability of precipitation is much higher than that of other variables, and that the latter are stationary, i.e. their influence is negligible, and droughts are responses to temporal variability in precipitation totals. Each of the drought indices used herein differs not only in basic concept, but also in individual spectral characteristics (e.g. Heim 2002). It is therefore considered preferable to use a whole suite of drought indices to account for the different behaviours of each index across a range of frequency domains. A number of studies (e.g. Trnka et al. 2009, Paulo et al. 2012) have demonstrated that, while most common drought indices (including those used in this study) show considerable capability in drought identification, differences exist that are significant enough to justify the use of several types of drought index. Combining the use of indices with those driven by precipitation facilitates better attribution of droughts and drought trends in terms of their main driving factors. Paulo et al. (2012) also showed that differences in formulation and spectral characteristics impact upon the number of severe and extreme droughts determined (with scPDSI showing higher drought frequency). Further, PDSI, in this study representing non-normalised indices, is negatively biased; this 


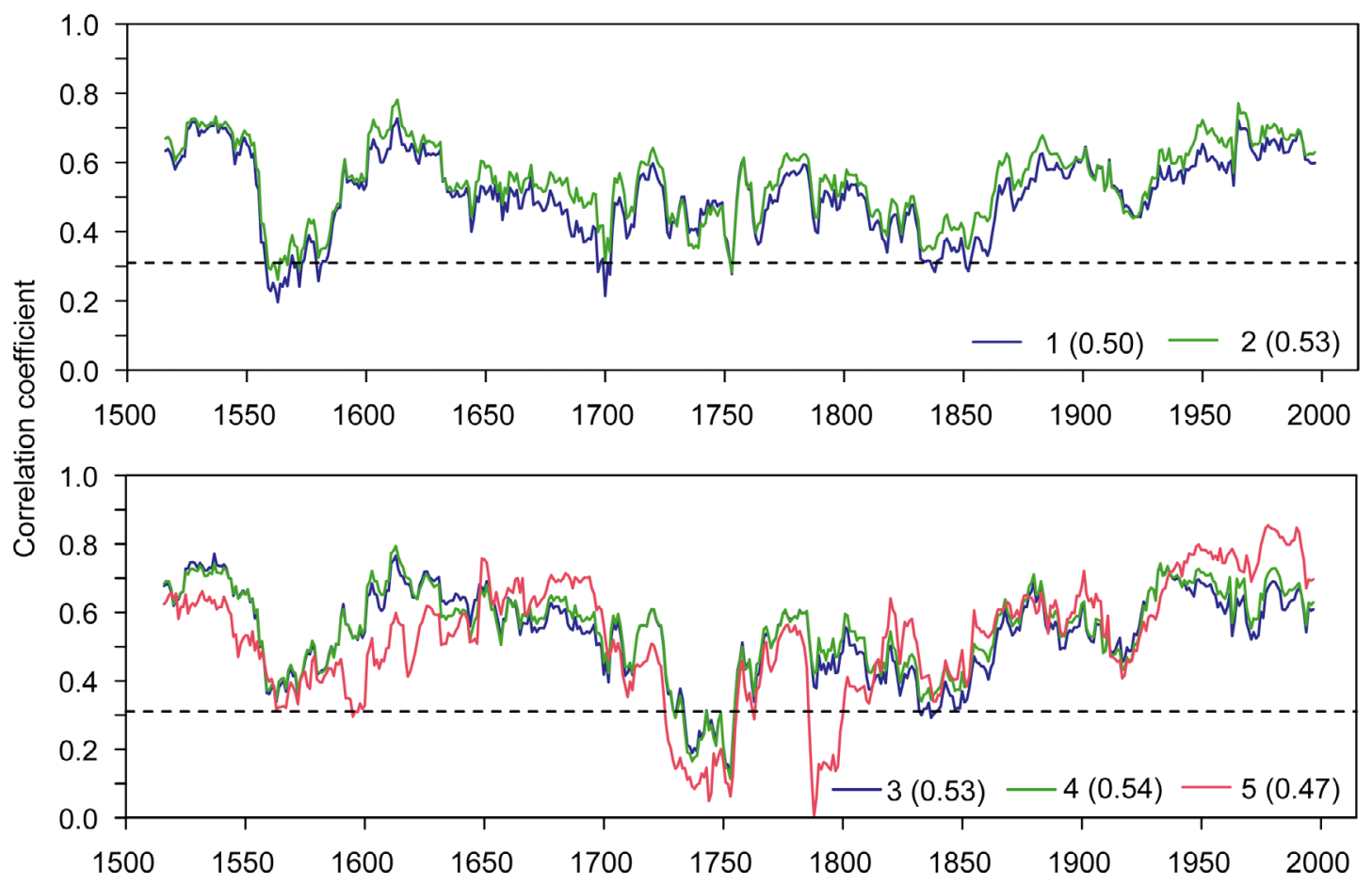

Fig. 7. Running 30 yr correlation coefficients of selected Czech drought indices series (1: JJA SPEI-3; 2: JJA Z-index; 3: summer half-year SPEI-6; 4: summer half-year Z-index; 5: annual scPDSI) with the Czech Lands JJA scPDSI series (CZs), after Cook et al. (2015). Significant positive correlations appear above the broken horizontal line; correlation coefficients between corresponding series are indicated in parentheses

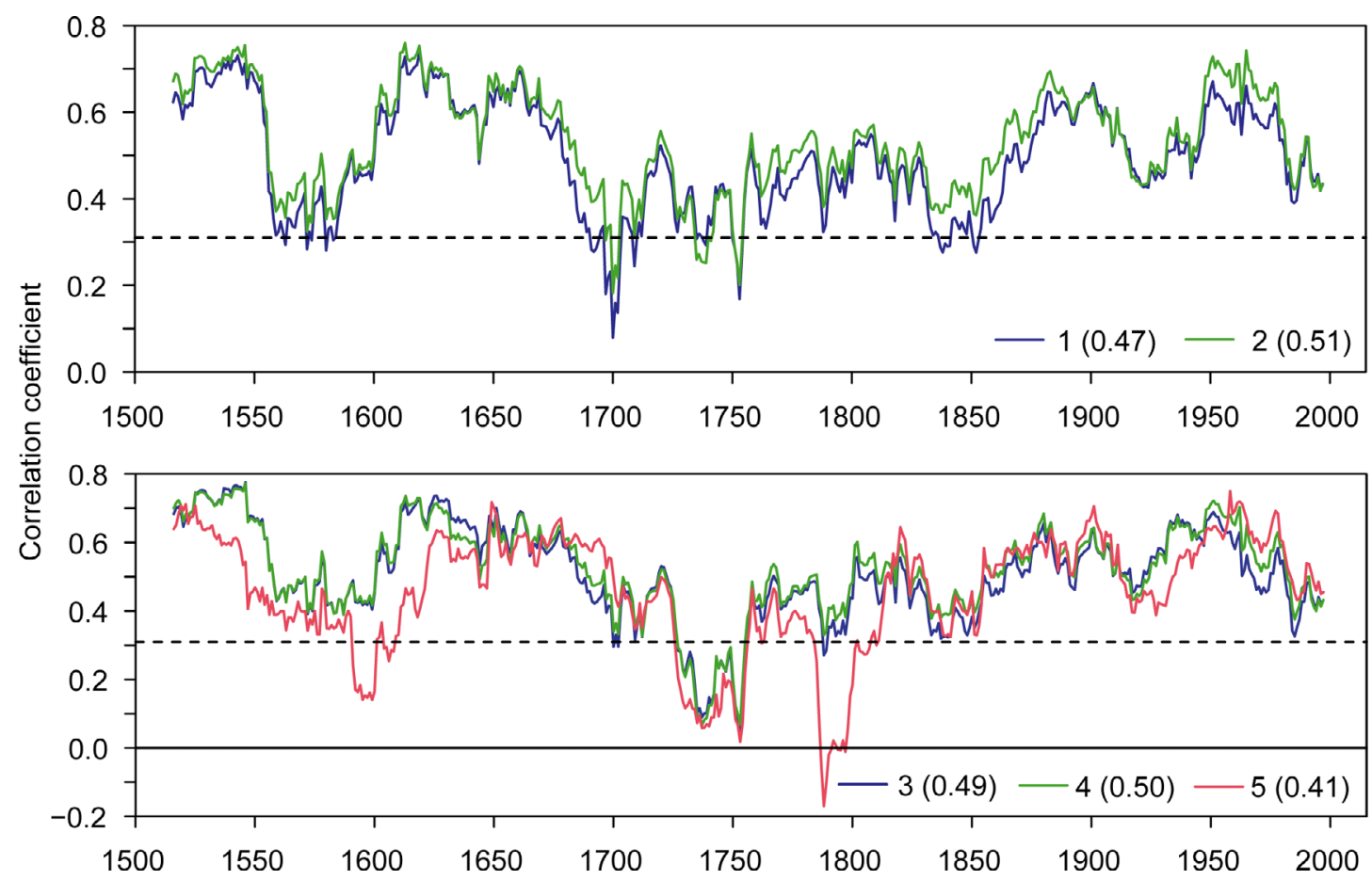

Fig. 8. Running 30 yr correlation coefficients of selected Czech drought indices series (1: JJA SPEI-3; 2: JJA Z-index; 3: summer half-year SPEI-6; 4: summer half-year Z-index; 5: annual scPDSI) with the central European lands JJA scPDSI series (CEs), after Cook et al. (2015). Significant positive correlations appear above the broken horizontal line; correlation coefficients between corresponding series are indicated in parentheses 
relates to its calibration using data from extremely dry and wet events and not seeking a probabilistic balance between dry and wet events.

Four drought indices were calculated from reconstructions of central European temperature and Czech precipitation series by Dobrovolný et al. (2010, 2015a, respectively); the uncertainties within them are discussed in detail in both papers. The use of central European temperature data rather than data for the Czech Lands is not a source of bias, since there is a high degree of similarity between this series and mean Czech temperatures series (Brázdil et al. $2012 a, b)$, as shown by the high correlation coefficients for the 2 series in the 1800-2007 period (see Section 2). More problematical is the use of the Czech seasonal precipitation reconstruction (Dobrovolný et al. 2015a), a situation arising out of its lesser explained variance in the 1804-1854 verification period, and its use of seasonal precipitation totals when monthly values are necessary for the calculation of drought indices. The way in which this problem was overcome in the calculation process is described in Section 2. Obviously, the monthly values for each index in the 1501-1803 period may be affected by the lack of monthly-resolved precipitation values. The value of such data would in any case be limited, as they could only consist of statistical extrapolation based on observed distribution over a long period. Aggregation of all drought indices to seasons and longer periods was therefore employed to minimise influences from the calculation procedure. As Figs. 1-3 show, the confidence intervals of all indices track the index values closely, showing a minimum influence of uncertainty, and demonstrating the robustness of the method used.

The use of both documentary and instrumental data for drought reconstructions raises the question of how the 2 types of data, and the method used for calculation of drought indices, might change the relative distribution of indices from the pre-instrumental (1501-1759) and the instrumental (1804-2015) periods. The 1760-1803 period, with its mixture of instrumental (temperature) and documentary (precipitation) data was excluded from this comparison. Fig. 9 shows examples of this comparison for JJA SPI3, JJA Z-index, summer half-year SPEI-6 and annual scPDSI. The relative distribution of drought indices for the pre-instrumental and instrumental datasets is very similar. This distribution does not deviate significantly from normal distribution, since the Q-Q plots in Fig. 9 approximate closely to straight lines. The variability of indices in the pre-instrumental and instrumental periods was compared using the $F$-test.
Data from the pre-instrumental period show higher variability compared with instrumental data for all index series. However, they are significantly higher (significance level $\alpha=0.05$ ) only for JJA Z-index and annual scPDSI.

\section{CONCLUSIONS}

This study takes a completely new direction in the study of the long-term fluctuations of droughts, in that it calculates drought indices from series of quantitatively reconstructed mean air temperatures and precipitation totals derived from documentary data dating back to AD 1501. The drought indices calculated for the pre-instrumental period are then used at the same level as those derived from temperature and precipitation measurements in the instrumental period to create a $515 \mathrm{yr}$ series in order to investigate long-term drought variability in the Czech Lands and Central Europe.

Despite great inter-annual and inter-decadal variability, no long-term trends are detectable in the series of Czech drought indices. The prevalence of extreme droughts in the pre-instrumental period is notable, with the most extreme drought occurring 1540, followed by 1590 and 1616, and the driest $30 \mathrm{yr}$ periods occurring in the 3 decades at the beginning of the 18th century and at its end. In the longer-term context, a clear tendency of increasing dryness appears in the late 20th and early 21st centuries according to drought indices that combine the effects of temperature and precipitation, such as SPEI, Zindex and scPDSI. This is an indication of the influence of rising air temperatures on increasing potential evapotranspiration in the context of recent global warming (Trnka et al. 2015a) and decreasing soil moisture (Trnka et al. 2015b).

The reconstructed $515 \mathrm{yr}$ series of drought indices for the Czech Lands provided only weak correlations with other European precipitation series, but compared well with precipitation and drought indices reconstructed from hydric-sensitive fir tree-ring series in southern Moravia (Brázdil et al. 2002, Büntgen et al. 2011a) as well as with a European OWDA JJA scPDSI reconstruction (Cook et al. 2015), thus facilitating cross-checking of the 2 methods of reconstruction. The methodological approach here applied has great potential for use in the creation of new drought series for Europe. Moreover, the reconstructed series of Czech drought indices will prove useful for comparisons with other European drought reconstructions. 

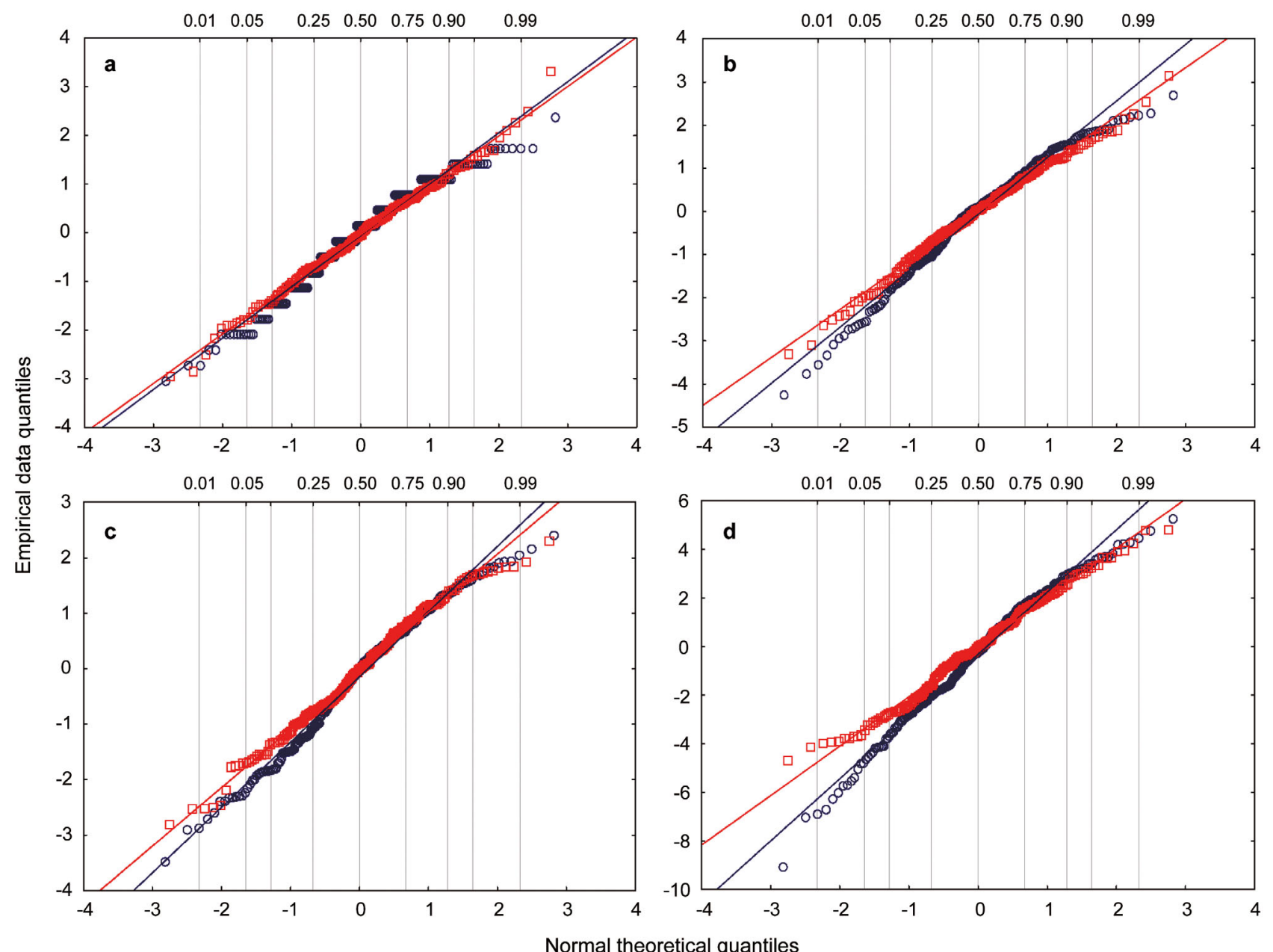

Fig. 9. Q-Q plots comparing distribution of reconstructed drought indices for the pre-instrumental (1501-1759, blue) and instrumental (1804-2015, red) periods in the Czech Lands: (a) JJA SPI-3, (b) JJA Z-index, (c) summer half-year SPEI-6, (d) annual scPDSI. Vertical straight lines indicate a comparison of distribution of indices against theoretical normal distribution

Acknowledgements. R.B. and P.D. acknowledge the support of the Grant Agency of the Czech Republic for project no. P209/11/0956, L.R. and H.V. for project no. 13-19831S and M.T. for project no. 13-04291S. R.B., P.D., M.T., U.B., L. ̌r. and P.Š. also acknowledge funding from the Ministry of Education, Youth and Sports of the Czech Republic within the National Sustainability Program I (NPU I). Tony Long (Svinošice) helped improve the English.

\section{LITERATURE CITED}

Barriendos M (2005) Climate and culture in Spain: religious responses to extreme climatic events in the Hispanic Kingdoms (16th-19th century). In: Behringer W, Lehmann H, Pfister C (eds) Kulturelle Konsequenzen der 'Kleine Eiszeit' - Cultural consequences of the 'Little Ice Age'. Vandenhoeck \& Ruprecht, Göttingen, p 379-414

Brázdil R, Trnka M (eds) (2015) Sucho v českých zemích: minulost, současnost, budoucnost (Drought in the Czech Lands: past, present and future). Centrum výzkumu globální změny Akademie věd České republiky, v.v.i., Brno ä Brázdil R, Štěpánková P, Kyncl T, Kyncl J (2002) Fir treering reconstruction of March-July precipitation in southern Moravia (Czech Republic), 1376-1996. Clim Res 20: 223-239

Brázdil R, Pfister C, Wanner H, von Storch H, Luterbacher J (2005) Historical climatology in Europe - the state of the art. Clim Change 70:363-430

Brázdil R, Trnka M, Dobrovolný P, Chromá K, Hlavinka P, Žalud Z (2009) Variability of droughts in the Czech Republic, 1881-2006. Theor Appl Climatol 97:297-315

Brázdil R, Dobrovolný P, Luterbacher J, Moberg A, Pfister C, Wheeler D, Zorita E (2010) European climate of the past 500 years: new challenges for historical climatology. Clim Change 101:7-40

Brázdil R, Bělínová M, Dobrovolný $\mathrm{P}$, Mikšovský J and others (2012a) Temperature and precipitation fluctuations in the Czech Lands during the instrumental period. Masaryk University, Brno

Brázdil R, Zahradníček P, Pišoft P, Štěpánek P, Bělínová M, Dobrovolný P (2012b) Temperature and precipitation fluctuations in the Czech Lands during the period of instrumental measurements. Theor Appl Climatol 110:17-34 Brázdil R, Dobrovolný P, Trnka M, Kotyza O and others 
(2013a) Droughts in the Czech Lands, 1090-2012 AD. Clim Past 9:1985-2002

Brázdil R, Kotyza O, Dobrovolný P, Řezníčková L, Valášek H (2013b) Climate of the sixteenth century in the Czech Lands. Masaryk University, Brno

> Brázdil R, Trnka M, Mikšovský J, Řezníčková L, Dobrovolný $P$ (2015) Spring-summer droughts in the Czech Land in 1805-2012 and their forcings. Int J Climatol 35:1405-1421

Brázdil R, Raška P, Trnka M, Zahradníček P and others (2016) The Central European drought of 1947: causes and consequences with particular reference to the Czech Lands. Clim Res 70:161-178

- Breshears DD, Cobb NS, Rich PM, Price KP and others (2005) Regional vegetation die-off in response to global-changetype drought. Proc Natl Acad Sci USA 102:15144-15148

Büntgen U, Brázdil R, Frank D, Esper J (2010) Three centuries of Slovakian drought dynamics. Clim Dyn 35:315-329

- Büntgen U, Brázdil R, Dobrovolný P, Trnka M, Kyncl T (2011a) Five centuries of Southern Moravian drought variations revealed from living and historic tree rings. Theor Appl Climatol 105:167-180

Büntgen U, Brázdil R, Heussner KU, Hofmann J and others (2011b) Combined dendro-documentary evidence of Central European hydroclimatic springtime extremes over the last millennium. Quat Sci Rev 30:3947-3959

Büntgen U, Tegel W, Career M, Krusic PJ, Hayes M, Esper J (2015) Commentary to Wetter et al. (2014): Limited treering evidence for a 1540 European 'Megadrought'. Clim Change 131:183-190

Byun H, Wilhite DA (1999) Objective quantification of drought severity and duration. J Clim 12:2747-2756

Cook ER, Seager R, Kushnir Y, Briffa KR and others (2015) Old World megadroughts and pluvials during the Common Era. Sci Adv 1:e1500561

Dai A (2011) Drought under global warming: a review. WIREs Clim Change 2:45-65

> Diodato N, Bellocchi G (2011) Historical perspective of drought response in central-southern Italy. Clim Res 49: 189-200

> Dobrovolný P, Brázdil R, Valášek H, Kotyza O, Macková J, Halíčková M (2009) A standard paleoclimatological approach to temperature reconstruction in historical climatology: an example from the Czech Republic, AD 1718-2007. Int J Climatol 29:1478-1492

> Dobrovolný P, Moberg A, Brázdil R, Pfister C and others (2010) Monthly and seasonal temperature reconstructions for Central Europe derived from documentary evidence and instrumental records since AD 1500. Clim Change 101:69-107

> Dobrovolný P, Brázdil R, Trnka M, Kotyza O, Valášek H (2015a) Precipitation reconstruction for the Czech Lands, AD 1501-2010. Int J Climatol 35:1-14

> Dobrovolný P, Rybníček M, Kolář T, Brázdil R, Trnka M, Büntgen U (2015b) A tree-ring perspective on temporal changes in the frequency and intensity of hydroclimatic extremes in the territory of the Czech Republic since 761 AD. Clim Past 11:1453-1466

> Domínguez-Castro F, Santisteban JI, Barriendos M, Mediavilla R (2008) Reconstruction of drought episodes for central Spain from rogation ceremonies recorded at the Toledo Cathedral from 1506 to 1900: a methodological approach. Global Planet Change 63:230-242

Domínguez-Castro F, Garcia-Herrera R, Ribera P, Barrien$\operatorname{dos} M(2010)$ A shift in the spatial patterns of Iberian droughts during the 17th century. Clim Past 6:553-563
Glaser R (2001) Klimageschichte Mitteleuropas. 1000 Jahre Wetter, Klima, Katastrophen. Primus Verlag, Darmstadt Glaser R (2008) Klimageschichte Mitteleuropas. 1200 Jahre Wetter, Klima, Katastrophen. Primus Verlag, Darmstadt

Heim RR (2000) Drought indices: a review. In: Wilhite DA (ed) Drought: a global assessment. Hazards and disasters series, Vol. 1. Routledge, New York, NY, p 159-167

Heim RR (2002) A review of twentieth-century drought indices used in the United States. Bull Am Meteorol Soc 83:1149-1165

Hlavinka P, Trnka M, Semerádová D, Dubrovský M, Zalud Z, Mozný M (2009) Effect of drought on yield variability of key crops in Czech Republic. Agric For Meteorol 149: 431-442

McKee TB, Doesken NJ, Kleist J (1993) The relationship of drought frequency and duration to time steps. In: Preprints, 8th Conference on Applied Climatology, January 17-22. Anaheim, CA, 17-22 January 1993. American Meteorological Society, Boston, MA, p 179-184

> Mishra AK, Singh VP (2010) A review of drought concepts. J Hydrol (Amst) 391:202-216

> Možný M, Brázdil R, Dobrovolný P, Trnka M and others (2016) Drought reconstruction based on grape harvest dates for the Czech Lands in AD 1499-2012. Clim Res 70: $119-132$

Niemeyer S (2008) New drought indices. In: López-Francos A (ed) Drought management: scientific and technological innovations. CIHEAM, Zaragoza, p 267-274

Palmer WC (1965) Meteorological drought. Office of Climatology Research Paper 45, US Weather Bureau, Washington, DC

Pauling A, Luterbacher J, Casty C, Wanner H (2006) Five hundred years of gridded high-resolution precipitation reconstructions over Europe and the connection to largescale circulation. Clim Dyn 26:387-405

> Paulo AA, Rosa RD, Pereira LS (2012) Climate trends and behaviour of drought indices based on precipitation and evapotranspiration in Portugal. Nat Hazards Earth Syst Sci 12:1481-1491

Pfister C (1988) Klimageschichte der Schweiz 1525-1860. Das Klima der Schweiz von 1525-1860 und seine Bedeutung in der Geschichte von Bevölkerung und Landwirtschaft, Band 1-2. Paul Haupt, Bern

Pfister C (1999) Wetternachhersage. 500 Jahre Klimavariationen und Naturkatastrophen (1496-1995). Paul Haupt, Bern

Pfister C, Wetter O, Brázdil R, Dobrovolný P and others (2015) Tree-rings and people-different views on the 1540 Megadrought. Reply to Büntgen et al. 2015. Clim Change 131: 191-198

> Piervitali E, Colacino M (2001) Evidence of drought in western Sicily during the period 1565-1915 from liturgical offices. Clim Change 49:225-238

Rybníček M, Čermák P, Prokop O, Žid T, Trnka M, Kolář T (2015) Oak (Quercus spp.) response to climate differs more among sites than among species in central Czech Republic. Dendrobiology (Pozn) 75:55-65

Stocker TF, Qin D, Plattner GK, Tignor M and others (eds) (2013) Climate change 2013: the physical science basis. Contribution of Working Group I to the fifth assessment report of the Intergovernmental Panel on Climate Change. Cambridge University Press, Cambridge

Trnka M, Dubrovský M, Svoboda M, Semerádová D, Hayes M, Žalud Z, Wilhite D (2009) Developing a regional drought climatology for the Czech Republic. Int J 
Climatol 29:863-883

Trnka M, Brázdil R, Balek J, Semerádová D and others (2015a) Drivers of soil drying in the Czech Republic between 1961 and 2012. Int J Climatol 35:2664-2675

Trnka M, Brázdil R, Možný M, Štěpánek P and others (2015b) Soil moisture trends in the Czech Republic between 1961 and 2012. Int J Climatol 35:3733-3747

van der Schrier G, Briffa KR, Jones PD, Osborn TJ (2006) Summer moisture variability across Europe. J Clim 19: 2818-2834

Vicente-Serrano SM, Beguería S, López-Moreno JI (2010) A multi-scalar drought index sensitive to global warming: the Standardized Precipitation Evapotranspiration Index. J Clim 23:1696-1718

Vogt JV, Somma F (eds) (2000) Drought and drought mitigation in Europe: advances in natural and technological

Editorial responsibility: Donald Wilhite (Guest Editor),

Lincoln, Nebraska, USA hazards research. Kluwer, Dordrecht

> Wetter O, Pfister C, Werner JP, Zorita E and others (2014) The year-long unprecedented European heat and drought of 1540-a worst case. Clim Change 125:349-363

Wilson RJS, Luckman BH, Esper J (2005) A 500 year dendroclimatic reconstruction of spring-summer precipitation from the lower Bavarian Forest region, Germany. Int J Climatol 25:611-630

Wu H, Svoboda MD, Hayes MJ, Wilhite DA, Wen F (2007) Appropriate application of the standardized precipitation index in arid locations and dry seasons. Int J Climatol 27 : 65-79

Zahradníček P, Trnka M, Brázdil R, Možný M and others (2015) The extreme drought episode of August 2011May 2012 in the Czech Republic. Int J Climatol 35: 3335-3352

Submitted: December 15, 2015; Accepted: February 28, 2016 Proofs received from author(s): June 1, 2016 